\title{
DATABASE HEALTH MONITORING (DHM) SEBAGAI ALAT MONITORING KESEHATAN DATABASE
}

\author{
Ary Budi Warsito ${ }^{1}$ \\ Muhamad Yusup ${ }^{2}$ \\ Rivai Sungkowo ${ }^{3}$ \\ Dosen STMIK Raharja Jurusan Teknik Informatika ${ }^{1}$, Dosen STMIK Raharja Jurusan Teknik \\ Informatika $^{2}$, Alumni Mahasiswa STMIK Raharja Jurusan Teknik Informatika ${ }^{3}$ \\ Email : arybudiwarsito@raharja.info, yusup@raharja.info, rivai@raharja.info
}

Diterima : 11 Juli 2016/Disetujui : 25 Juli 2016

\begin{abstract}
DSS (Decision Support Systems) has the notion that a computer-based system that presents and process information that allows decisions to be more productive, dynamic and innovative [1]. In this study, a concept with the name DHM (Database Health Monitoring). DHM concept is a form of development of the DSS is a concept of how to analyze the health of a database in which the level of health in the database is measured by the number of empty fields. To calculate the number of empty fields required sql queries which query results are then processed into a protocol JSON (JavaScript Object Notation) is a concise format computer data exchange [6]. In JSON protocol is what ultimately made a dashboard. The results are displayed in the form of dashboards to facilitate leadership read the information received. In addition, the leadership does not need direct access to the database to get information.
\end{abstract}

Keywords : DSS, JSON, DHM, Dashboard

ABSTRAK

DSS (Decision Support Systems) memiliki pengertian yaitu sistem berbasis komputer yang menyajikan dan memproses informasi yang memungkinkan pembuatan keputusan menjadi lebih produktif, dinamis dan inovatif ${ }^{[1]}$. Pada penelitian ini dibuat sebuah konsep dengan nama DHM (Database Health Monitoring). Konsep DHM ini merupakan sebuah bentuk pengembangan dari DSS yaitu sebuah konsep bagaimana menganalisa kesehatan sebuah database dimana tingkatan kesehatan pada database diukur berdasarkan jumlah field yang kosong. Untuk menghitung jumlah field yang kosong dibutuhkan query sql yang kemudian hasil query tersebut diproses menjadi protokol JSON (JavaScript Object Notation) yaitu sebuah format ringkas pertukaran data komputer ${ }^{[6]}$. Pada protokol JSON inilah yang akhirnya dijadikan sebuah dashboard. Hasil yang ditampilkan berupa dashboard untuk memudahkan pimpinan membaca informasi yang diterima. Selain itu pimpinan tidak perlu mengakses langsung ke dalam database untuk mendapatkan sebuah informasi.

Kata Kunci: DSS, JSON, DHM, Dashboard

\section{PENDAHULUAN}

Mungkin tanpa kita sadari setiap hari kita selalu berhadapan dengan berbagai informasi. Bentuk informasi yang ada di internet ini sangat luar biasa banyak sehingga kita perlu jeli dalam memilah informasi. Dengan adanya kebutuhan data informasi yang cepat, maka informasi langsung bisa di olah dengan seketika dan kita pun langsung mendapatkan informasinya saat itu juga. Namun jika kita melihat dengan jeli ada suatu informasi yang tidak kalah penting untuk pengambilan keputusan. Tanpa informasi ini sistem informasi yang beredar bahkan yang sering kita baca di internet menjadi tidak berarti. Informasi yang disajikan menjadi kurang berarti jika kita gagal mengalami pemasukan informasi. 
DSS (Decision Support Systems) adalah sistem berbasis komputer yang menyajikan dan memproses informasi yang memungkinkan pembuatan keputusan menjadi lebih produktif, dinamis dan inovatif ${ }^{[1]}$. Dalam berbagai proses manajemen, termasuk manajemen akademik, proses pengambilan keputusan telah banyak bergantung pada DSS yang telah dikembangkan, seperti pada saat keputusan penerimaan mahasiswa baru, evaluasi prestasi akademik, yudisium, dan penentuan mahasiswa berprestasi.

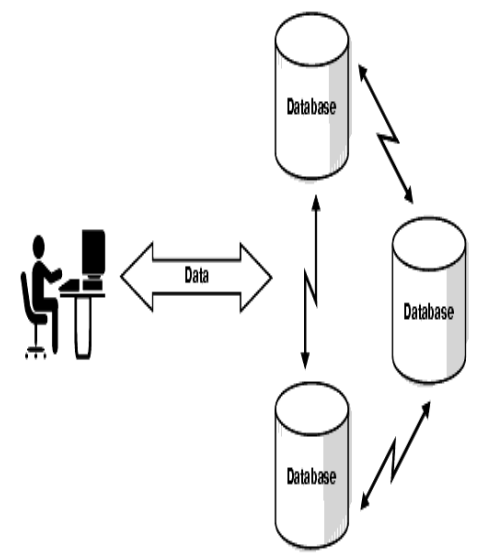

Gambar 1. Proses Mendapatkan Data

Gambar diatas menjelaskan proses mendapatkan data informasi dimana data tersebut tersimpan di dalam database yang tanpa kita sadari sering mengalami kendala dalam proses penyajiannya. Sering kita disulitkan untuk memahami informasi yang didapatkan akibatnya informasi yang disajikan menjadi kurang berarti.

DSS tidak hanya di gunakan mengambil keputusan sesuai dengan gambar diatas. DSS sendiri pun bisa di gunakan untuk mengambil keputusan pada sumbernya sendiri yang memberikan informasi. dengan kata lain DSS yang dimaksud disini dapat di gambarkan sebagai berikut jika salah satu badan kita ada yang sakit maka yang sakit tersebut langsung memberi sinyal ke otak kita. setelah itu otak akan mengolah informasi yang di mengerti oleh kita. Dari pendekatan ini bagaimana kita tahu database kita sedang mengalami sakit? . cara yang praktis adalah mendatangi langsung ke sumbernya dan melakukan perbaikan. tapi pada kenyataanya kita tahu database sakit karena memang di dalam database sudah sakit terlebih dahulu sehingga pencegahan di bilang terlambat. Dari pendekatan ini dapat di ambil konsep bagaimana DSS yang di bangun ini dapat memberikan informasi ke kita bahwa database sedang tidak dalam kondisi baik dalam arti sudah di kasih Alarm terlebih dahulu.

Oleh karena itu pada penelitian ini mencoba mengangkat sebuah sistem DSS yang dapat menyajikan informasi kesehatan di dalam database sebagai pengambilan keputusan sehingga pencegahan dapat di maksimalkan.

\section{PERMASALAHAN}

Saat ini dalam melakukan pemeriksaan kesehatan database baik itu field di dalam table yang masih kosong, kita masih harus masuk ke dalamnya yaitu ke dalam database langsung. Meskipun cara seperti itu bisa digunakan, namun terkadang informasi yang dihasilkan tidak mudah dipahami oleh sebagian besar orang dan membutuhkan waktu yang lama.

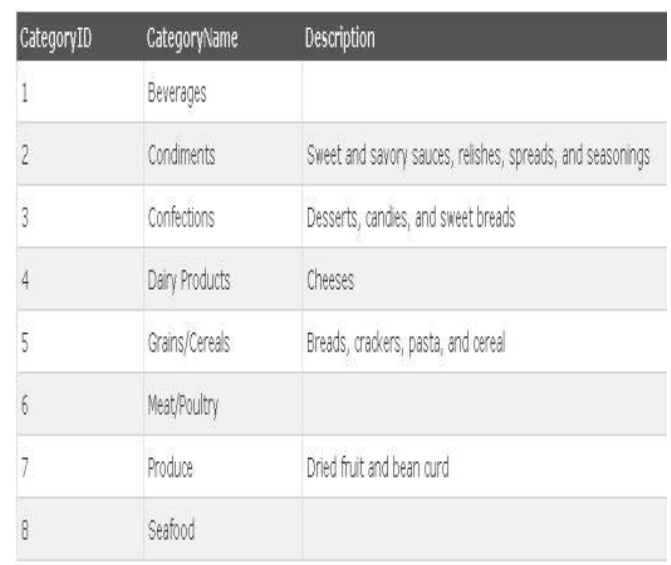

Gambar 2. Contoh Pemeriksaan Kesehatan Database 
Pada gambar 2 diatas adalah contoh bagaimana cara melakukan pemeriksaan kesehatan pada database dimana dari 8 field di record Description, terdapat 3 field yang tidak memiliki nilai atau field tersebut kosong. Jika kita ingin menghitung jumlah field yang kosong dibutuhkan sebuah Query SQL select count (*) from Categories where Description == "'"; yang secara langsung menghitung jumlah field kosong pada record Description. Selain itu hanya orang yang bertanggung jawab terhadap database dalam hal ini database administrator yang dapat melakukan pemeriksaan kesehatan database sehingga dibutuhkan waktu untuk menyajikan informasi agar mudah dipahami oleh sebagian besar orang.

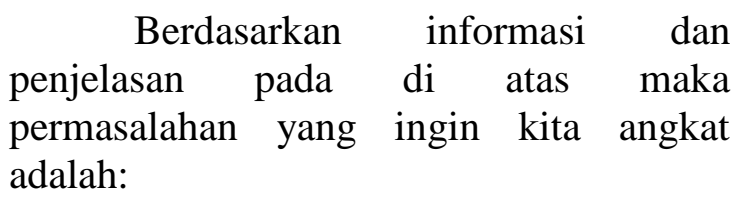

1. Bagaimana kita dapat mengetahui kesehatan di dalam sebuah database baik itu field di dalam table dengan tampilan yang mudah dipahami dan lebih informatif?

2. Bagaimana pemimpin instansi pendidikan dengan mudah dan cepat mendapatkan informasi dari kesehatan database?

3. Bagaimana mengubah hasil informasi ke dalam bentuk grafik agar memudahkan pemimpin instansi pendidikan dalam mengambil keputusan?

\section{LITERATURE REVIEW}

Beberapa Literature review tersebut adalah sebagai berikut :

1. Penelitian ini dilakukan oleh Yosep Agus Pranoto, M.Aziz Muslim dan Rini Nur Hasanah pada tahun 2013 yang berjudul "Rancang Bangun dan Analisis Decision Suport System Menggunakan Metode
Analytical Hierarchy Process untuk Penilaian Kinerja Karyawan". Penelitian ini menggunakan metode AHP (Analytical Hierarchy Process) melakukan penilaian kinerja karyawan dengan memanfaatkan primary key pada database untuk menghindari adanya data ganda serta kesalahan baik itu dalam proses perhitungan gaji atau menghindari kesalahan jika terdapat nama karyawan yang sama $^{[2]}$.

2. Penelitian ini dilakukan oleh Untung Rahardja, Dina Fitria Murad dan Siti Chalifatullah pada tahun 2008 yang berjudul "Periodic Historical System Sebagai Evaluasi Strategis Dalam Mendukung Pengambilan Keputusan Manajemen". Penelitian ini membuat sebuah aplikasi yang dapat menghasilkan informasi yang akurat dari waktu ke waktu untuk membantu manajemen dalam pengambilan kebutusan ${ }^{[3]}$.

3. Penelitian ini dilakukan oleh Widyat Nurcahyo dan Maimunah pada tahun 2009 yang berjudul "Pengambilan Keputusan Sistem Produksi Dengan Metode Simulasi Komputer". Penelitian ini memakai model simulasi untuk melihat hasil dari hipotesa atau kebijakan pada sistem dengan tujuan memperkecil keterlambatan produksi terhadap kehilangan penjualan ${ }^{[4]}$.

4. Penelitian ini dilakukan oleh Henderi, Untung Rahardja, Qory Oktisa Aulia dan Muhamad Hendri dengan judul "Dashboarding Information Systems For The Education Sector: Aplication And Methodologies". Penelitian ini menghasilkan sebuah sistem yang dapat menampilkan informasi dalam bentuk dashboarding, visual, real time dan on line sehingga mampu menerapkan 
prinsip early warning, self monitoring dan constant reminding ${ }^{[5]}$.

\section{PEMECAHAN MASALAH}

Dengan melihat permasalahanpermasalahan seperti pada gambaran diatas solusi yang tepat untuk mengatasi permasalahan tersebut adalah menggunakan sebuah konsep baru yaitu Database Health Monitoring (DHM).

\section{Database Health Monitoring} (DHM) sebagai sebuah terobosan baru yang berfungsi untuk memecahkan masalah pada pemeriksaan kesehatan database dengan menggunakan grafik sebagai media penyampaian informasi agar mudah dipahami dan lebih informatif.

DHM dapat dikatakan sebagai bentuk dari DSS dimana dapat menampilkan hasil dari sebuah informasi melalui sebuah bentuk grafik agar lebih mudah dipahami. Selain itu bentuk grafik sangat sederhana yang memungkinkan untuk ditempatkan secara strategis.

DHM memiliki ciri khas dalam memecahkan permasalahan yang sering dihadapi, diantaranya adalah sebgai berikut:

1. DHM hanya menampilkan informasi mengenai kesehatan database yang memiliki field kosong.

2. DHM menyajikan informasi dalam bentuk gauge chart yaitu sebuah bentuk grafik yang mirip dengan speedometer pada kendaraan bermotor.

3. DHM menggunakan protokol JSON (JavaScript Object Notation) yaitu sebuah format ringkas pertukaran data komputer ${ }^{[6]}$ dalam mendapatkan sebuah data.

4. DHM dapat diimplementasikan ke dalam bentuk dahsboard yaitu suatu model antarmuka sisteminformasi yang dianalogikan seperti dashboard sebuah mobil yang mudah untuk dipelajari dan sangat strategis bagi driver ${ }^{[5]}$.

Apabila seorang pemimpin ingin mengetahui informasi seperti data mahasiswa yang belum mengisi alamat atau kode pos, maka pimpinan dapat langsung memperoleh informasi tersebut pada dashboard biodata mahasiswa.

Adapun keunggulan dari $D H M$ yaitu sebelum digunakan metode $D H M$ sistem tidak memiliki dahsboard untuk melakukan monitoring terhadap kesehatan pada database. Selain itu DHM yang menggunakan protokol JSON dapat dengan mudah mengimplementasikannya ke dalam berbagai perangkat salah satunya adalah perangkat mobile.

\section{yar Biodata}

\section{Main()}

\{

Insert column terisi

\section{Cek column Biodata}

IF Biodata != null

Insert terisi $=1$

IF Biodata $==$ null

Insert terisi $=0$

COUNT terisi

selesai

)

\section{Gambar 3. Algoritma DHM}

Pada gambar 3 diatas adalah algoritma dari proses perhitungan field yang kosong pada database. Dengan memanfaatkan beberapa column tambahan yang kemudian apabila data terisi maka field pada column tambahan tersebut akan terisi dengan angka 1 (satu). Kemudian kita hanya perlu menjumlahkan seluruh field pada column tambahan tersebut untuk mendapatkan jumlah field yang kosong. 


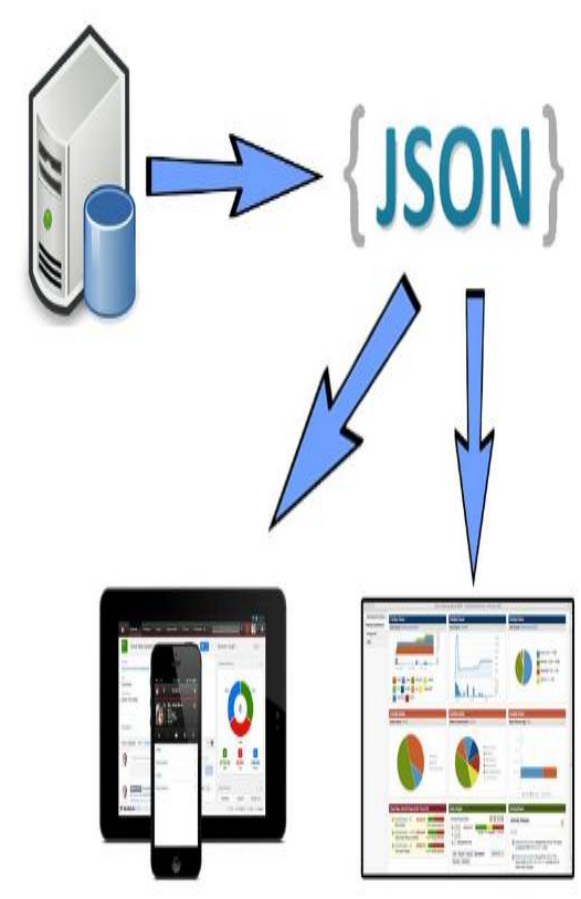

Gambar 4. Proses Penyajian Informasi

Pada gambar 4 diatas merupakan alur proses penyajian data mulai dari database hingga ke dalam bentuk dashboard. Data tersimpan di dalam database yang kemudian diolah menjadi sebuah JSON. Dari JSON tersebut data akan diolah kembali yang kemudian dapat dijadikan sebuah grafik atau dapat diimplementasikan juga ke dalam perangkat mobile.

\section{IMPLEMENTASI}

Database Health Monitoring (DHM) dibangun dengan menggunakan protokol JavaScript Object Notation (JSON) berfungsi untuk memberi kemudahan kepada pimpinan dalam mendapatkan sebuah informasi yang mudah dipahami dan lebih informatif. Informasi yang dihasilkan akan disajikan dalam bentuk grafik untuk mempermudah membacanya.

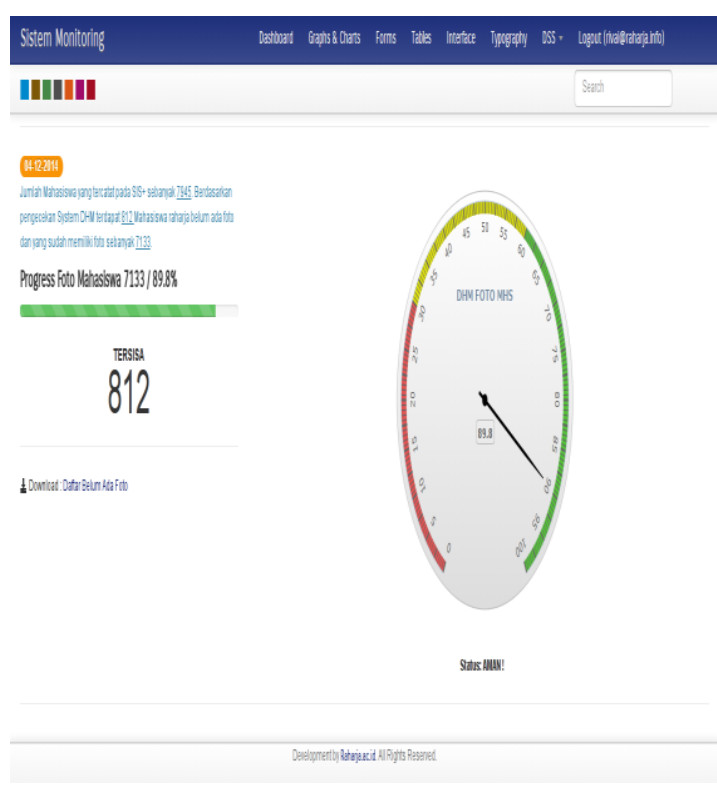

Gambar 5 DHM Biodata Foto

Tampilan diatas merupakan tampilan $D H M$ biodata foto dimana pada grafik tersebut menunjukkan indikator kesehatan database dalam status AMAN. Status tersebut diperoleh dengan melihat jumlah field yang kosong dalam hal ini adalah field pada column foto.

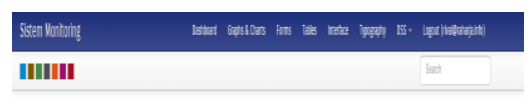

NONTOPNGG BOOATA MHHASSSWHA

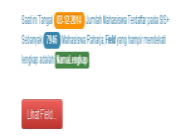

Gambar 6. DHM Biodata Mahasiswa

Gambar diatas menunjukkan kesehatan database yang kurang baik atau kurang sehat. Keterangan kurang sehat tersebut diperoleh berdasarkan jumlah field dari biodata mahasiswa dimana masih banyak terdapat beberapa field yang masih kosong. 


\section{KESIMPULAN}

Dari uraian diatas, dapat diambil kesimpulan bahwa dengan menggunakan DHM ini sangat cocok untuk membantu pimpinan dalam memonitoring kesehatan database secara tepat dan mudah dipahami dan lebih informatif. $D H M$ ini memiliki beberapa manfaat kegunaan diantaranya:

1. DHM mampu mengetahui kondisi kesehatan database dengan tampilan yang mudah dipahami.

2. $D H M$ dapat memberikan informasi secara cepat kepada pemimpin instansi pendidikan.

3. DHM dapat mengubah informasi ke dalam bentuk grafik untuk memudahkan pemimpin instansi pendidikan dalam mengambil keputusan.

\section{DAFTAR PUSTAKA}

[1] Burstein, F.dan Holsapple, C.W.,"Handbook on Decision Support System 1", Springer, Heidelberg 2008.

[2] Agus Pranoto, Yosep. Muslim, M.Aziz. dan Nur Hasanah, Rini "Rancang Bangun dan
Analisis Decision Suport System Menggunakan Metode Analytical Hierarchy Process untuk Penilaian Kinerja Karyawan". Jurnal EECCIS Vol. 7, No. 1, Juni 2013

[3] Rahardja, Untung. Fitria Murad, Dina. dan Chalifatullah, Siti "Periodic Historical System Sebagai Evaluasi Strategis Dalam Mendukung Pengambilan Keputusan Manajemen". Jurnal CCIT. Perguruan Tinggi Raharja. 2008

[4] Nurcahyo, Widyat dan Maimunah "Pengambilan Keputusan Sistem Produksi Dengan Metode Simulasi Komputer". Jurnal CCIT. Perguruan Tinggi Raharja. 2009

[5] Henderi, Rahardja. Untung, Aulia. Qory Oktisa. Hendri. Muhamad. "Dashboarding Information Systems For The Education Sector: Aplication And Methodologies". Jurnal CCIT. Perguruan Tinggi Raharja. 2011

[6] Sidik,

Betha. "Pemrograman PHP" .Bandung:Informatika Bandung. 